\title{
Removal of Acid Green 25 from Aqueous Solution by Adsorption
}

\author{
R. PARIMALAM ${ }^{1,}$ V. RAJ ${ }^{2}$, AND P. SIVAKUMAR $^{3}$ \\ Department of Chemistry \\ Sri Meenakshi Government College for Women \\ Madurai, Tamil Nadu, 625 002, India \\ Department of Chemistry, Periyar University \\ Salem, Tamil Nadu, 636 011, India \\ Department of Chemistry, Arignar Anna Government Arts College \\ Namakkal, Tamil Nadu. 637 002, India \\ pari_ramachandran@yahoo.co.in
}

Received 18 August 2011; Accepted 26 October 2011

\begin{abstract}
The adsorptive removal of Acid Green 25 by Ananas Comosus (L) Activated carbon was investigated in this study. The effects of initial dye concentration, contact time, $\mathrm{pH}$ and temperature were studied for the adsorption of Acid Green 25 in batch mode. At $100 \mathrm{mg} / \mathrm{L}$ of initial dye concentration the adsorbent removes $182.6 \mathrm{mg} / \mathrm{g}$ of dye from solution; it further increases on increasing the temperature. The calculated values of $\Delta \mathrm{G}^{\mathrm{o}}$ indicate that the adsorption process is spontaneous, negative $\Delta \mathrm{H}^{\circ}$ indicate that the adsorption process is exothermic and the positive value of $\Delta \mathrm{S}^{\circ}$ indicates the increase in randomness. The rate of dye adsorption follows pseudo second order model with an $r^{2}$ value of 0 . 999. Standard adsorption isotherms were used to fit the experimental equilibrium data. The Langmuir, Freundlich, and Tempkin models are appropriate to explain the adsorption phenomenon with good fit.
\end{abstract}

Keywords: Adsorption, Acid Green 25, Ananas Comosus (L) carbon, isotherm, kinetics, thermodynamics.

\section{Introduction}

Adsorption has proven to be one of the most effective physicochemical methods for textile wastewater treatment. Acid dyes are water soluble anionic dyes and are applied to nylon, wool, silk, and modified acrylics ${ }^{1}$. There is a growing interest ${ }^{2}$ in preparing substitute for activated carbon, the conventional and low cost adsorbent recommended to remove dyes from colored effluents. In past, activated carbon was prepared ${ }^{3}$ from coal/lignite (42\%), wood/coconut ( $45 \%$ ) or animal bones and was designated as mineral carbon and bone char, respectively. In the second group the choice is very broad and varies from wood bark of different trees to fruits, plants and cereals waste. The encyclopedic edition of Gupta and $\mathrm{Ali}^{4}$ complies the alternative materials subjected with carbonization for environmental 
applications and particularly, in dye removal like: almond shells, olive stones, rice husk. A challenge in the field of activated carbon production is to produce specific materials with a given properties including pore size distribution and surface area from low cost precursors and at low temperature. In recent years considerable researchers have been focused on low cost alternative and innovative natural materials used in the production of carbonaceous solids and tested in dye adsorption include, bagasse ${ }^{5}$, bamboo $^{6}$, Cassava peel $^{7}$, cobs $^{8}$, cotton $^{5}$ stalks $^{9}$, palm seed ${ }^{10}$, peanut hulls ${ }^{3,6}$, plum kernels ${ }^{11,12}$, rice husk ${ }^{13}$, sawdust ${ }^{13,14}$ and straw ${ }^{5}$. Naturasorbents have been mainly obtained from plant wastes like maize, coconut and sugar cane and fruits peel like orange and banana. The adsorption properties of seeds, stones and pits have been reported only for carbonized samples. Although there is not clear evidence that the non-carbonized forms exhibit low efficiency, recent research suggests that carbonization yielding high specific surface area magnetitudes is the only way of preparing effective adsorbents from naturally occurring materials.

The present study was under taken to evaluate the efficiency of a carbon adsorbent prepared from acid activated Ananas Comosus leaves for removal of dye in aqueous solution in order to design adsorption treatment system, knowledge of kinetic and mass transfer process is essential. In this paper we have reported the applicability of kinetic and mass transfer models for the adsorption of Acid green 25 (AG 25) on to activated carbon.

\section{Experimental}

Raw material (Ananas comosus leaves) used for the preparation of activated carbon was collected locally, cut into pieces of 1 to $2 \mathrm{~cm}$ size, dried in sunlight for 7 days. The dried material soaked in a boiling solution of $10 \% \mathrm{H}_{3} \mathrm{PO}_{4}$ for $1 \mathrm{~h}$ and kept at room temperature for overnight, then the material was separated, air dried and carbonized in muffle furnace at $400^{\circ} \mathrm{C}$ for $20 \mathrm{~min}$. The carbonized material was powdered, activated in a muffle furnace at $600^{\circ} \mathrm{C}$ for a period of $10 \mathrm{~min}$. Then the material was washed with plenty of distilled water to remove residual acid, dried, sieved $45 \mu \mathrm{m}$ to $300 \mu \mathrm{m}$ size and stored in a tight lid container for further adsorption studies.

\section{Adsorbate Preparation}

All the chemicals used are reagent grade. An anionic dye (Acid green 25) having molecular formula $\mathrm{C}_{28} \mathrm{H}_{20} \mathrm{~N}_{2} \mathrm{Na}_{2} \mathrm{O}_{8} \mathrm{~S}_{2}$ (Mol.wt 622.57) with CI. No.61570 and $\lambda_{\max } 640 \mathrm{~nm}$. Stock solution $(1000 \mathrm{mg} / \mathrm{L})$ of Acid Green (Figure 1) is prepared by dissolving appropriate amount of dye (based on $\%$ of purity) in $1000 \mathrm{ml}$ of double distilled water. The stock solution was diluted with double distilled water to obtain required standard solution.

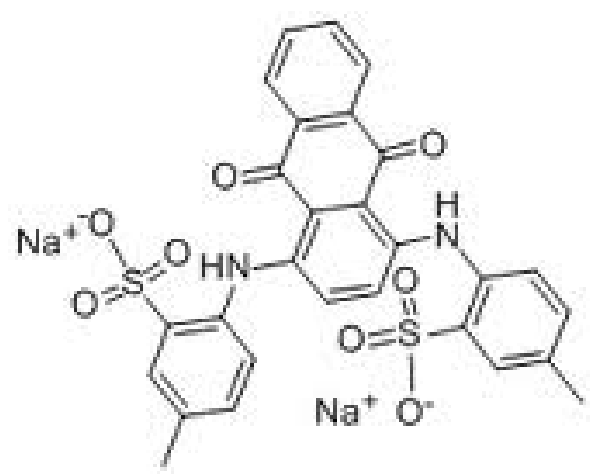

Figure 1. Structure of Acid Green 25. 


\section{Physicochemical Characteristics of Activated Carbon}

FTIR Analysis

The Fourier transform infrared (FTIR) spectra recorded for the ACC to analyze the surface functional groups of the prepared activated carbon. To obtain the observable adsorption spectra, the activated carbon was ground to a very fine powder and then dried at $120^{\circ} \mathrm{C}$ for at least $24 \mathrm{~h}$. The dilution and homogenization of the fine carbon sample to approximately 0.1 wt $\%$ with $\mathrm{KBr}$ (spectroscopic grade) were carried out with additional grinding Disc (12.7 $\mathrm{mm}$ I.D and approximately $1 \mathrm{~mm}$ thickness) was prepared in a manual hydraulic press (15 tons max.) at 10 tons for a pressing time of $0.5 \mathrm{~min}$. The spectra were measured and recorded (4000- $\left.400 \mathrm{~cm}^{-1}\right)$ in the Parkin Elmer 16 PC spectrometer.

\section{Surface Morphology and Structural Analysis}

SEM photograph of the carbon sample were examined by scanning electron microscope (Hitachi S-3400N). X-ray diffraction patterns of the activated carbon sample were studied using DELL GX 270 and the patterns were recorded over a 2-theta (20) range of 10-75.

\section{Determination of Surface Area}

Surface area of the activated carbon were measured by using Acetic acid titration method.

\section{Physicochemical Characteristics}

Physiochemical characteristics were measured as per the standard testing procedure ${ }^{15}$.

\section{Adsorption studies}

The adsorption experiments were carried out in $250 \mathrm{~mL}$ tight lid glass bottle (Borosil-R) by agitating $100 \mathrm{mg}$ of adsorbent with $200 \mathrm{~mL}$ of known initial concentration say $(25,50,75$ and $100 \mathrm{mg} / \mathrm{L}$ respectively) of Acid Green 25 solution. All the experiments (except the study of $\mathrm{pH}$ effect) were carried out at a $\mathrm{pH}$ of 6.45 (natural $\mathrm{pH}$ of Acid Green aqueous solution). The effect of $\mathrm{pH}$ was studied by adjusting the $\mathrm{pH}$ of the adsorptive solution 2 to 11 using $0.1 \mathrm{~N} \mathrm{HCl}$ and $0.1 \mathrm{~N} \mathrm{NaOH}$. The contents of the flasks were agitated by placing them in a temperature controlled orbital shaker. The mixture was withdrawn at specified interval then centrifuged using electrical centrifuge at 5000rpm for $10 \mathrm{~min}$ and unabsorbed supernatant liquid was analyzed for residual Acid Green 25 concentration spectrophotometrically (using Elico make Bio-UV visible spectrometer (BL-198)) at $\lambda_{\max } 640$. All the experiments were conducted in duplicate and mean of the two values were taken for calculation. Maximum deviation is $4 \%$.

\section{Desorption Studies}

Desorption studies as a function of $\mathrm{pH}$ were conducted to analyze the possibility of reuse the adsorbent for further adsorption and to make the process more economical. After adsorption experiments the dye loaded carbon washed gently with double distilled water to remove any un-adsorbed dye present. Desorption studies were conducted using several such carbon samples. $50 \mathrm{mg}$ of the dye loaded carbon agitated above the equilibrium time with $50 \mathrm{ml}$ of double distilled water of various $\mathrm{pH}$ and the desorbed dye was estimated as stated in the adsorption studies ${ }^{16}$.

\section{Results and Discussion}

\section{Adsorbent Characteristics}

Some of the important physiochemical properties of Ananas comosus (L) activated carbon (ACC) are given in Table 1 . The conductivity of activated carbon was very low, which indicates the absence of more exchangeable sites. Like most of the naturally occurring plant materials ACC also has more volatile matter, which could have originated from the parent material. 
Generally, an adsorbent with higher bulk density need not be regenerated frequently because it can hold more adsorbate per unit volume ${ }^{17}$. Bulk density of ACC is found to be very close with the commercial activated carbon. The Phosphoric acid activated carbon has the surface area of $908 \mathrm{~m}^{2} \mathrm{~g}^{-1}$. This well close to the commercial activated carbon as well as other carbon prepared from waste plant materials by the past researchers.

Table 1. Physicochemical characteristics of ACC.

\begin{tabular}{lll}
\hline & Properties & Values \\
\hline 1 & $\mathrm{pH}$ & 8.93 \\
2 & conductivity. $\mathrm{mS} \mathrm{cm}^{-1}$ & 0.09 \\
3 & Moisture content, \% & 7.4 \\
4 & Ash, \% & 15.4 \\
5 & Volatile matter, \% & 18.3 \\
6 & Matter soluble in water, \% & 0.42 \\
7 & Matter soluble in $0.25 \mathrm{~N} \mathrm{HCl,} \mathrm{\%}$ & 1.28 \\
8 & Bulk density, g mL ${ }^{-1}$ & 0.43 \\
9 & Specific gravity & 0.92 \\
10 & Porosity, \% & 53.26 \\
11 & Surface area ${ }^{2} / \mathrm{g}^{2}$ & 908 \\
12 & Methylene Blue Value, $\mathrm{mg} \mathrm{g}^{-1}$ & 345 \\
13 & Iodine Number, $\mathrm{mg} \mathrm{g}^{-1}$ & 948 \\
14 & Fixed Carbon, \% & 58.9 \\
15 & Yield \% & 54.6 \\
\hline
\end{tabular}

The XRD spectrum of the adsorbent showed the broad peaks, which indicate the presence of amorphous form of carbon. It does not give any major peak which could be due to lack of inorganic and crystalline substance in the activated carbon.

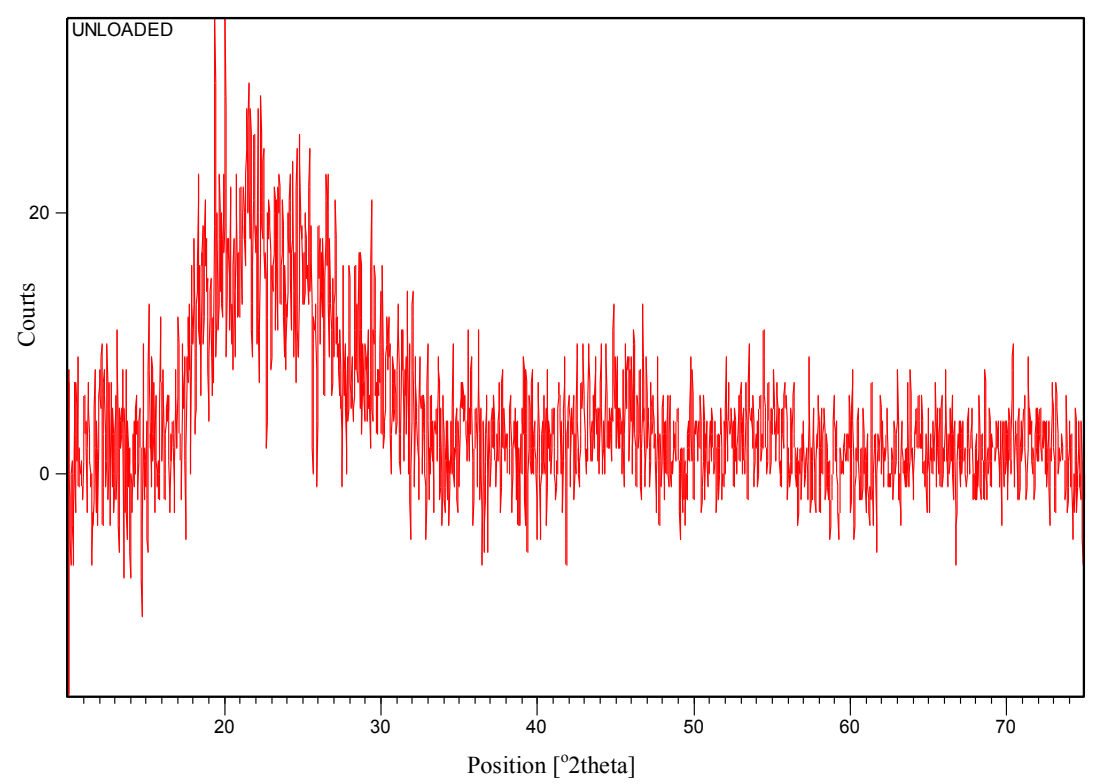

Figure 2. XRD Spectrum of ACC. 
The SEM photographs ascertained that the relative pores with wide ranging cracks. The macro pores clearly visible facilitating the easy diffusion of more number of dye molecules in to the pore structure and also adsorbed on the surface of the adsorbent (Figure 3).
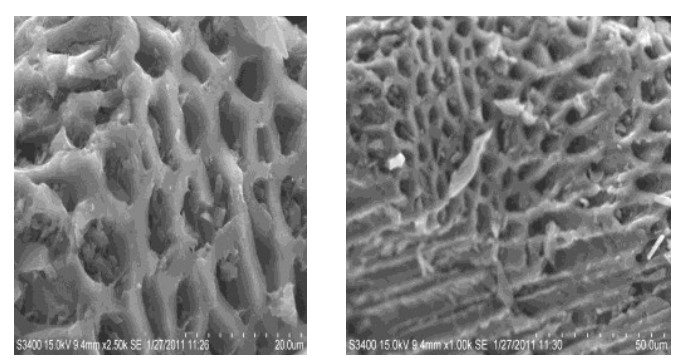

Figure 3. SEM Photograph of ACC (at $2500 \mathrm{X}$ and 1000X).

The FT-IR spectra of the activated carbon showed the characteristic bands at $3787 \mathrm{~cm}^{-1}$ due to $\mathrm{O}-\mathrm{H}$ stretching, $3428 \mathrm{~cm}^{-1}$ represents $\mathrm{O}-\mathrm{H}$ stretching vibrations of the carboxylic acid, peaks at $2336.84 \mathrm{~cm}^{-1}$ represents the $\mathrm{C}-\mathrm{C}$ stretching, peaks at $1563.36 \mathrm{~cm}^{-1}$ represents the $\mathrm{C}=\mathrm{C}$ stretching, peak appears at $1441 \mathrm{~cm}^{-1}$ shows the $\mathrm{C}-\mathrm{H}$ bend in $\mathrm{CH}_{3}$. The presence of $\mathrm{C}-\mathrm{O}$ stretching was indicated that the presence of peaks at $1138.04 \mathrm{~cm}^{-1}$ and $1099.46 \mathrm{~cm}^{-1}$ and $1022.31 \mathrm{~cm}^{-1}$. The peak appears at $797.56 \mathrm{~cm}^{-1}$ is due to $\mathrm{C}-\mathrm{H}$ deformation (Figure 4). The presence of these functionalities will increase the heterogeneity and there by increases the adsorption.

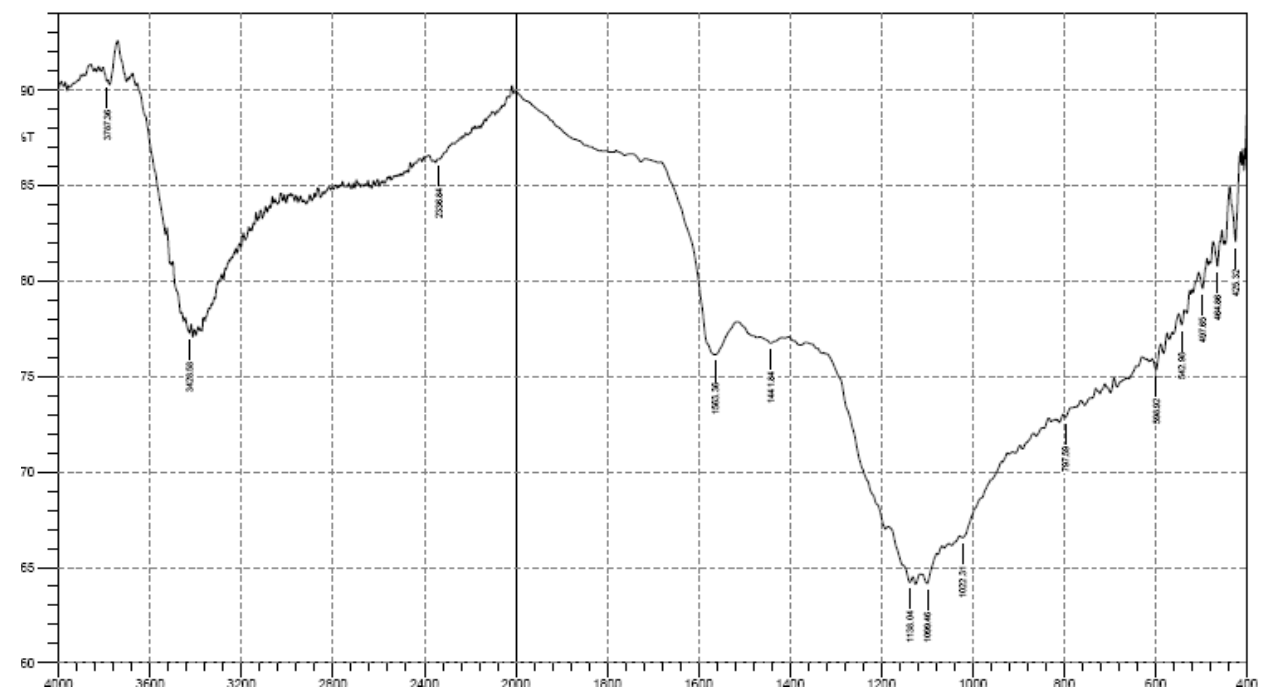

Figure 4. FT-IR Spectrum of ACC.

\section{Effect of $p H$}

Adsorption is also affected by change in $\mathrm{pH}$ of the solution ${ }^{18,19}$ as shown in Figure 5 . The dependence of adsorption process on $\mathrm{pH}$ of dye solution was studied by varying $\mathrm{pH}$ of the dye solution from 2 to 11 . The hydrogen ion concentration $(\mathrm{pH})$ primarily affects the degree of ionisation of the dyes and the surface properties of the adsorbents. The $\%$ of dye adsorbed decreased from 94.2 to 65.4 with increase in $\mathrm{pH}$ from 2 to 11 at temperature at $25^{\circ} \mathrm{C}$. At 
higher $\mathrm{pH}$ the surface of carbon becomes negative which repels the negative dye molecules, hence, the dye adsorption decreases.

\section{Effect of Agitation Time and Initial Dye Concentration on Adsorption}

In order to evaluate the maximum adsorption capaity of ACC it is necessary to get the equilibrium sorption data at various initial dye concentration. The results of sorption of AG 25 on to ACC at various concentrations are shown in Fig. 6. The uptake of dye increased from $49.87 \mathrm{mg} \mathrm{g}^{-1}$ to $182.6 \mathrm{mg} \mathrm{g}^{-1}$ with increase in the initial dye concentration from 25 to $100 \mathrm{mg} \mathrm{L}^{-1}$.

The initial dye concentration provides necessary driving force to overcome the resistance to the mass trasfer between the aqueous and solid phase $\mathrm{e}^{20}$. The increase in dye concentration diminishes the resistance and makes more contact between dye and adsorbent. Availability of dye molecules in the vicinity of adsorbent also increases while increasing the concentration, which results in high uptake of dye at higher concentration.

As seen from the Figure 6 maximum amount of dye is adsorbed in the initial 40 min of contact time and the rate decreases thereafter and reaches an equilibrium at $70 \mathrm{~min}$. The results indicate that there is no change in sorption capacity after $70 \mathrm{~min}$. Therefore $90 \mathrm{~min}$ is fixed at the agitation time for isotherm studies.

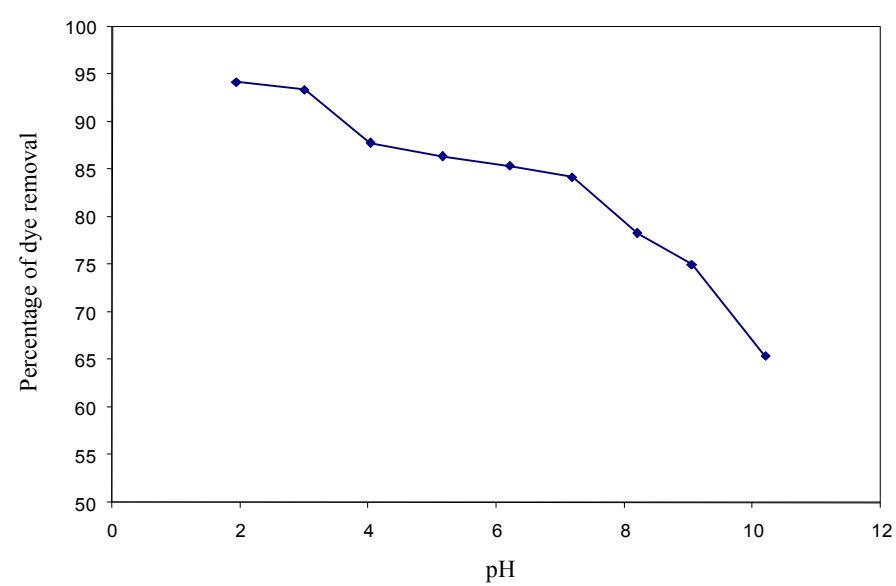

Figure 5. Effect of $\mathrm{pH}$ on the adsorption of AG 25 onto ACC.

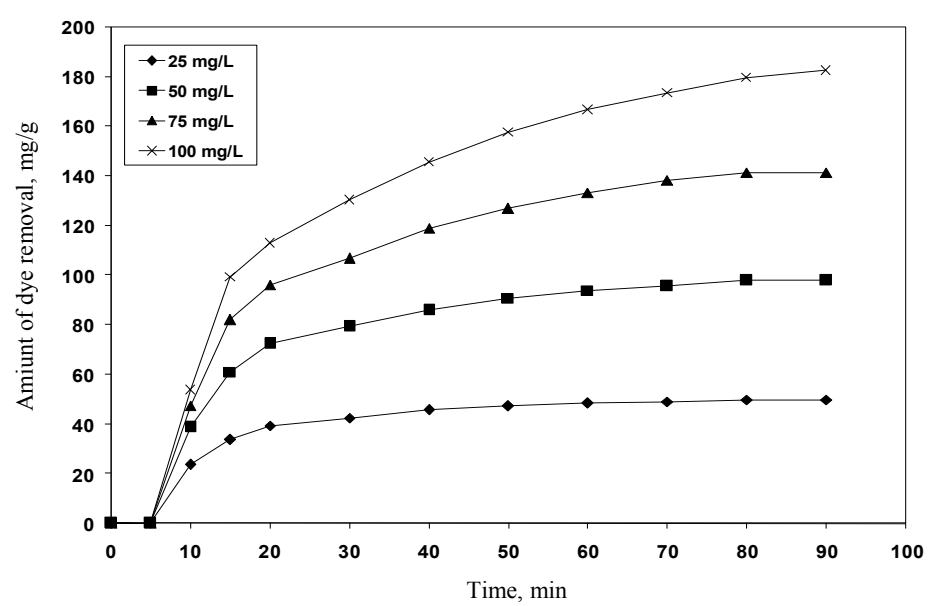

Figure 6. Effect of agitation time on the removal of AG 25 onto ACC at $303 \mathrm{~K}$. 


\section{Effect of Temperature on Dye Removal}

Figure 7 represents the uptake of AG 25 onto ACC at temperatures of 303,313 and $323 \mathrm{~K}$ keeping the initial dye concentration at $75 \mathrm{mgL}^{-1}$. The equilibrium sorption capacity of AG25 onto ACC increases from $141.49 \mathrm{mg} \mathrm{g}^{-1}$ to $144.43 \mathrm{mg} \mathrm{g}^{-1}$ while increasing the temperature from 303 to $323 \mathrm{~K}$.

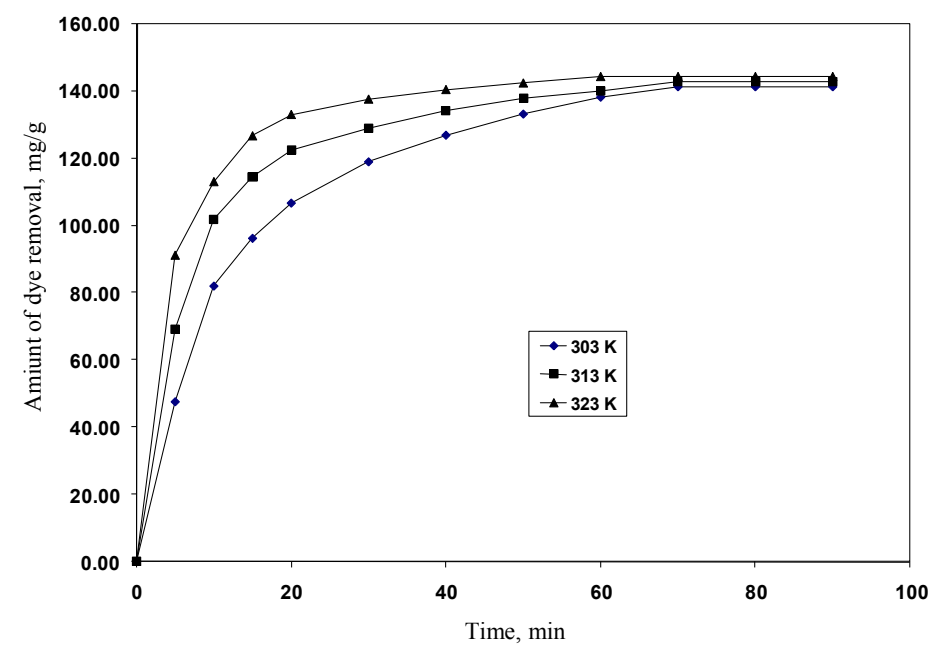

Figure 7. Effect of Temperature on the removal of AG 25 onto ACC.

\section{Adsorption Kinetics}

In order to investigate the adsorption of acid green on the surface of ACC, different kinetic models are used to examine the controlling mechanism of adsorption process. The proposed kinetic models are based on literature for sorption processes and adsorption capacity of adsorbent. In this study, pseudo-first-order kinetics model, pseudo-second-order kinetic model and intra particle diffusion model are used to analyze the kinetics of adsorption.

\section{Pseudo First Order Kinetic Model}

This model assumes that the rate of change of solute uptake with time is directly proportional to difference in saturation concentration and the amount of solid uptake with time. In most cases the adsorption reaction preceded by diffusion through a boundary, the kinetics follows the pseudo first-order model proposed by Lagergren ${ }^{21}$. The integrated linear form of the model is

$$
\log \left(\mathrm{q}_{\mathrm{e}}-\mathrm{q}_{\mathrm{t}}\right)=\mathrm{k}_{1} / 2.303 \times \mathrm{t} .
$$

Figure 8 shows a plot $\log \left(\mathrm{q}_{\mathrm{e}}-\mathrm{q}_{\mathrm{t}}\right)$ versus $\mathrm{t}$ give a straight line with the slope $-\mathrm{k}_{1} / 2.303$ and intercept $\log \mathrm{q}_{\mathrm{e}}$ which allows calculation of adsorption rate constant $\mathrm{k}_{1}$ and equilibrium adsorption capacity $\mathrm{q}_{\mathrm{e}(\mathrm{cal})}$. From the Figure 8, it is observed that the experimental data points does not fit a staight line. The results are presented in Table 2. The applicability of Lagergren model suggests the formation of monomolecular layer of dye species onto surface of adsorbent. The first order constant ranged from $5.78 \times 10^{-2} \mathrm{~min}^{-1}$ to $7.89 \times 10^{-2} \mathrm{~min}^{-1}$. The $\mathrm{q}_{\mathrm{e}(\mathrm{cal})}$ and $\mathrm{q}_{\mathrm{e}(\mathrm{exp})}$ values are not closer with each other. The correlation coefficients $r^{2}$ found to be range from 0.9504 to 0.9849 for the pseudo first order kinetic models, which are relatively low. It may be concluded that the 
kinetics of Acid green on ACC is not probably following the pseudo first order kinetics. Hence the adsorption of AG25 onto ACC is not diffusion controlled phenomena.

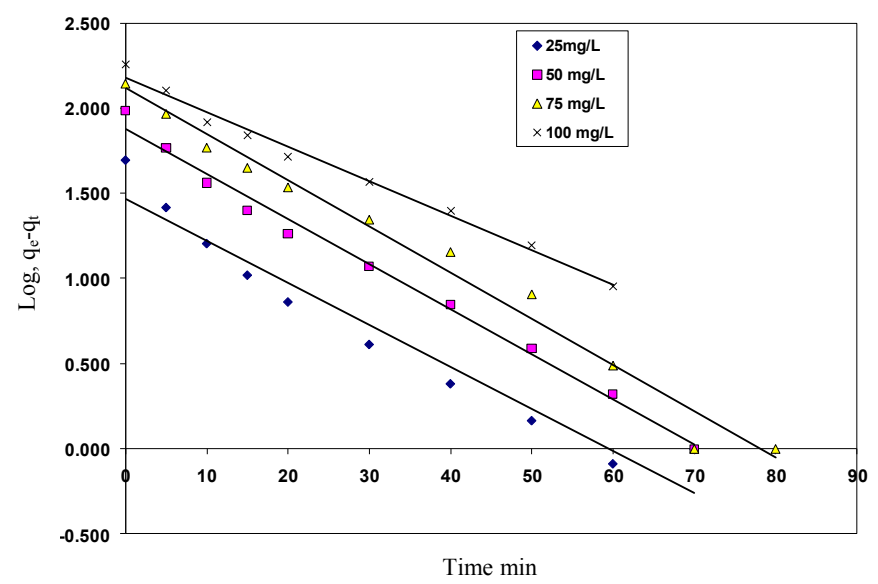

Figure 8. Pseudo first order plot for adsorption AG 25 onto ACC at $303 \mathrm{~K}$.

\section{Pseudo Second Order Kinetic Model}

The adsorption process with chemisorption being the rate control follows pseudo second order kinetic model ${ }^{22}$. The sorption kinetics may be represented by pseudo-second-order model.

$$
\mathrm{t} / \mathrm{q}_{\mathrm{t}}=1 / \mathrm{k}_{2} \mathrm{q}_{\mathrm{e}}^{2}+\mathrm{t} / \mathrm{q}_{\mathrm{e}}
$$

Figure 9 shows that the plot of $t / q_{t}$ versus $t$ is a straight line with slope of $1 / \mathrm{q}_{\mathrm{e}}$ and intercept $1 / \mathrm{k}_{2} \mathrm{q}_{\mathrm{e}}$. The calculated value of $\mathrm{k}_{2}, \mathrm{q}_{\mathrm{e}}$ and their corresponding regression coefficient $\left(r^{2}\right)$ values are presented in Table 2. The value of regression coefficient is greater than 0.999 , which confirms that the sorption kinetics of AG 25 follows a pseudo second order process. The calculated $\mathrm{q}_{\mathrm{e}}$ values are very close to that of experimentally obtained $\mathrm{q}_{\mathrm{e}}$. The adsorption of AG 25 on ACC can be better explained by pseudo second order kinetic model than that of pseudo first order kinetic model.The similar results were reported for the adsorption of Brilliant green dye on Kaolin ${ }^{23}$.

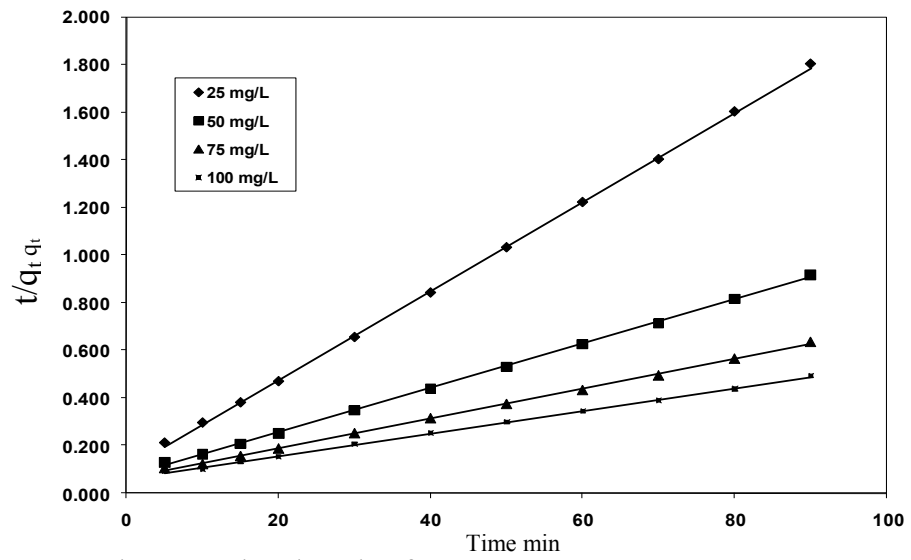

Figure 9. Pseudo second order plot for adsorption AG 25 onto ACC at $303 \mathrm{~K}$. 
Table 2. Calculated kinetic parameters for the adsorption of AG 25 onto ACC at various concentrations and temperatures.

\begin{tabular}{|c|c|c|c|c|c|c|c|}
\hline $\begin{array}{c}\text { Concentration } \\
\mathrm{mg} / \mathrm{L}\end{array}$ & 25 & 50 & 75 & 100 & $\begin{array}{c}\text { Temp }^{\circ} \\
\text { C } 30\end{array}$ & 40 & 50 \\
\hline \multicolumn{8}{|l|}{ First order kinetics } \\
\hline $\mathrm{k}_{1} \times 10^{-2}, \min ^{-1}$ & 0.0571 & 0.0610 & 0.06241 & 0.04698 & 0.0578 & 0.05988 & 0.07899 \\
\hline qe cal, mgg $^{-1}$ & 29.62 & 75.613 & 131.673 & 152.756 & 122.123 & 90.552 & 79.94 \\
\hline qe exp, $\mathrm{mgg}^{-1}$ & 49.87 & 97.90 & 141.49 & 182.60 & 141.49 & 143.03 & 144.43 \\
\hline $\mathrm{r}^{2}$ & 0.9482 & 0.9913 & 0.982 & 0.9883 & 0.9849 & 0.9664 & 0.9504 \\
\hline \multicolumn{8}{|l|}{ Second order kinetic } \\
\hline $\mathrm{k}_{2} \times 10^{-4}, \mathrm{~g} \mathrm{mg}^{-1} \mathrm{~min}^{-1}$ & 34.38 & 12.37 & 6.36 & 3.59 & 6.24 & 1.273 & 2.4 \\
\hline Qecal, $\mathrm{mgg}^{-1}$ & 53.475 & 107.526 & 157.23 & 212.76 & 158.73 & 151.5 & 149.25 \\
\hline $\mathrm{h}$ & 9.831 & 14.3 & 15.723 & 16.25 & 15.72 & 29.21 & 53.47 \\
\hline$r^{2}$ & 0.9997 & 0.9995 & 0.9991 & 0.9990 & 0.9991 & 0.9998 & 0.9999 \\
\hline \multicolumn{8}{|l|}{$\begin{array}{l}\text { Intra particle } \\
\text { diffusion model }\end{array}$} \\
\hline Kdiff, $\mathrm{mgg}^{-1} \mathrm{~min}$ & 4.347 & 6.723 & 9.648 & 11.834 & 10.21 & 7.31 & 5.628 \\
\hline$r^{2}$ & 0.989 & 0.974 & 0.992 & 0.998 & 0.992 & 0.971 & 0.940 \\
\hline 1 & 22.22 & 48.81 & 62.08 & 72.87 & 62.08 & 89.36 & 107.4 \\
\hline
\end{tabular}

Intraparticle Diffusion Model

In this model, it is assumed that the mechanisum for dye removal by adsorption on a sorbent material is taking place through four steps (a) migration of dye molecules from bulk solution to the surface of the adsorbent through bulk diffusion, (b) diffusion of dye molecules through the boundary layer to the surface of the adsorbent via film diffusion; (c) the transport of the dye molecules from the surface to the interior pores of the particle occur through intra-particle diffusion or pore diffusion mechanism and (d) the adsorption of dye at an active site on the surface of material by chemical reaction via ion-exchange, complexation and/or chelation. The adsorption process is a diffusive mass transfer process where the rate can be expressed in terms of the square root of time $(\mathrm{t})$. The intra-particlediffusion model is expressed as follows ${ }^{24}$.

$$
\mathrm{q}_{\mathrm{t}}=\mathrm{k}_{\mathrm{i}} \mathrm{t}^{0.5}+1
$$

where $\mathrm{q}_{\mathrm{t}}$ is the fraction dye uptake $(\mathrm{mg} / \mathrm{g})$ at time $\mathrm{t}, \mathrm{k}_{\mathrm{i}}$ is the intraparticle diffusion rate constant $\left(\mathrm{mg} /\left(\mathrm{g} \mathrm{min}{ }^{0.5}\right)\right)$ and 1 is the intercept $(\mathrm{mg} / \mathrm{g})$. A plot of $\mathrm{q}_{\mathrm{t}}$ versus $\mathrm{t}^{0.5}$ (Figure 10) will give $k_{i}$ as slope and 1 as intercept and results are presented in Table 2. The 1 represents the effect of boundary layer thickness. Minimum is the intercept length, adsorption is less boundary layer controlled.

From the Figure 10, the plots are non linear in nature but careful observation infer that data points can be better represented by double linear with difference in slope $\left(k_{i}\right)$ and intercept 1 . In this first straight line, the sudden increase (within a short time period) in slope signifies that the dye molecules are transported to the external surface of the ACC particle through film diffusion and its rate is very fast. After that, dye molecules are entered into the ACC particle by intra-particle diffusion through pore, which is represented in second straight line. Both the lines does not pass through the origin that concludes that both film diffusion and intra-particle diffusion are simultaneously occuring during the adsorption of acid green onto ACC. Similar result is observed for the adsorption of cationic dye using silkworm pupa as adsorbent ${ }^{25}$. 


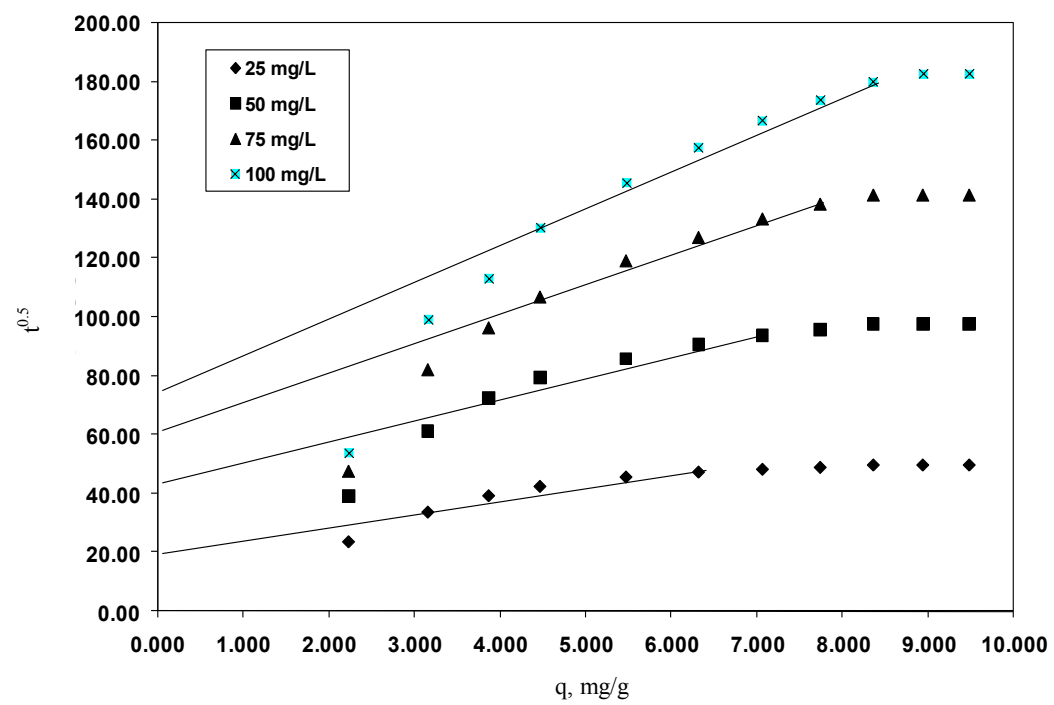

Figure 10. Intra particle diffusion for the adsorption AG 25 on to ACC at $303 \mathrm{~K}$.

\section{Equilibrium Isotherm Modelling}

Adsorption properties and equilibrium parameters, commonly known as adsorption isotherms, describe how the adsorbate interact with adsorbents and comprehensive understanding of the nature of interaction. Isotherm help to provide information about the optimum use of adsorbents. In order to optimize the design of an adsorption system to remove dye from solutions, it is essential to establish the most appropriate correlation for the equilibrium curve. There are several isotherm equations available for analyzing experimental sorption equilibrium parameters. However the most common types of isotherms are the Langmuir and Freundlich models.

\section{Langmuir Isotherm}

Langmuir ${ }^{26}$ proposed a theory to describe the adsorption of gas molecules onto metal surfaces. The Langmuir adsorption isotherm has found successful application to many other real sorption processes of monolayer adsorption. Langmuir's model of adsorption depends on the assumption that intermolecular forces decrease rapidly with distance and consequently predicts the existence of monolayer coverage of the adsorbate at the outer surface of the adsorbent. The isotherm equation further assumes that adsorption takes place at specific homogeneous sites within the adsorbent. It is then assumed that once a dye molecule occupies a site, no further adsorption can takes place at the site. Moreover, the Langmuir equation is based on the assumption of a structurally homogeneous adsorbent where all sorption sites are identical and energetically equivalent. Theoretically, the sorbent has a finite capacity for the sorbate. Therefore, a saturation value is reached beyond which no further sorption can takes place. The saturated or monolayer capacity can be represented by the expression:

$$
\frac{C_{e}}{q_{e}}=\frac{1}{Q_{0} b}+\frac{C_{e}}{Q_{0}},
$$

where $\mathrm{Q}_{\mathrm{o}}$ is a constant which signifies the adsorption of the monolayer capacity of the adsorbent $\left(\mathrm{mg} \mathrm{g}^{-1}\right)$; $b$ is the Langmuir constant related to the adsorption energy $\left(\mathrm{dm}^{3} \mathrm{mg}^{-1}\right)$. 
The plot of $\mathrm{C}_{\mathrm{e}} / \mathrm{q}_{\mathrm{e}} v s \mathrm{C}_{\mathrm{e}}$ gives a straight line with a linear regression coefficient of 0.9942 to 0.9891 when a temperature rises from $30^{\circ}$ to $50^{\circ} \mathrm{C}$ (Figure 11). From the intercept and slope of such plot, constants $\mathrm{Q}_{0}$ and $\mathrm{b}$ were evaluated. A dimensionless equilibrium parameter, $\mathrm{R}_{\mathrm{L}}$ can express the essential characteristics of Langmuir isotherm.

$$
R_{L}=\frac{1}{1+b \cdot C_{0}}
$$

The value of $R_{L}$ indicate the type of isotherm to be either irreversible $\left(R_{L}=0\right)$ favorable $\left(0<\mathrm{R}_{\mathrm{L}}<1\right)$; linear $\left(\mathrm{R}_{\mathrm{L}}=1\right)$; or unfavorable $\left(\mathrm{R}_{\mathrm{L}}>1\right)$. In the present study, the value of $\mathrm{R}_{\mathrm{L}}$ was less than 0.5 indicating the Langmuir adsorption isotherm to be a favorable adsorption isotherm.

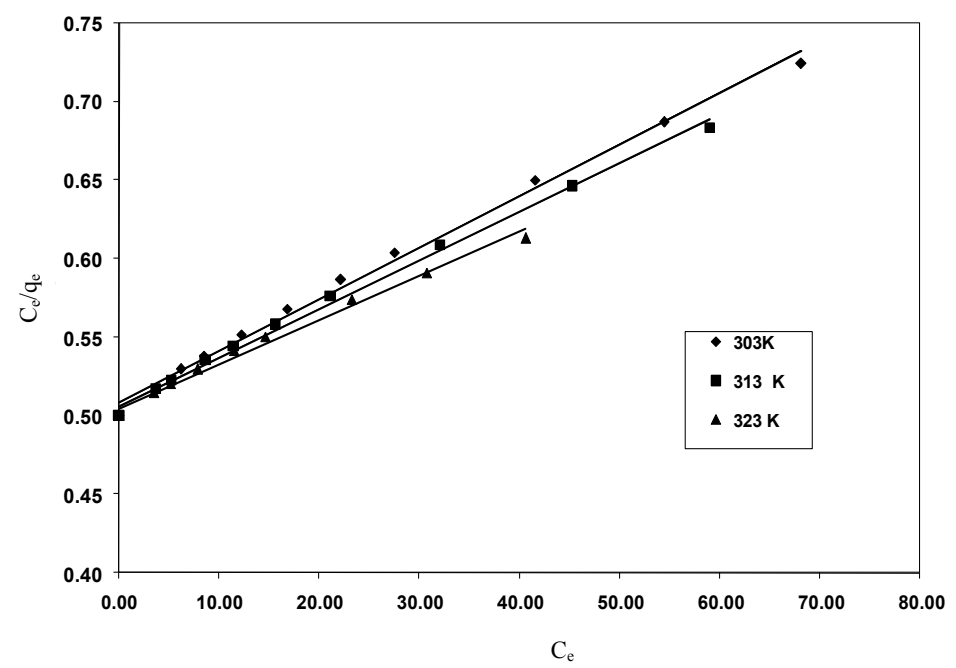

Figure 11. Langmuir isotherm for the adsorption AG 25 on to ACC at various temperatures.

\section{Freundlich Isotherm}

The Freundlich ${ }^{27}$ equation is an emprical equation employed to describe heterogeneous systems, in which it is characterized by the heterogenity factor $1 / \mathrm{n}$. Hence, the emprical equation can be written:

$$
\mathrm{q}_{\mathrm{e}}=\mathrm{K}_{\mathrm{F}} \mathrm{C}_{\mathrm{e}}^{1 / \mathrm{n}}
$$

where $\mathrm{q}_{\mathrm{e}}$ is solid phase sorbate concentration in equilibrium $(\mathrm{mg} / \mathrm{g}), \mathrm{C}_{\mathrm{e}}$ is liquid phase sorbate concentration in equilibrium $(\mathrm{mg} / \mathrm{L}), \mathrm{K}_{\mathrm{F}}$ is Freundlich constant $(\mathrm{L} / \mathrm{g})$ and $1 / \mathrm{n}$ is the heterogeneity factor were determined from a plot $\log \mathrm{C}_{\mathrm{e}} V s \log \mathrm{q}_{\mathrm{e}}$ are shown in Figure 12 and the results are shown in Table 3. This isotherm is another form of the Langmuir approach for adsorption on an "amorphous" surface. The amount of adsorbed material is the summation of adsorption on all sites. The Freundlich isotherm describes reversible adsorption and is not restricted to the formation of the monolayer. The Freundlich equation predicts that the dye concentration on the adsorbent will increase so long as there is an increase in the dye concentration in the liquid.

The Freundlich constant, $K_{F}$ increased with increase in temperature. The value of $n$ is greater than 1.0 indicating the adsorption AG 25 on to ACC is favourable. There is no 
remarkable difference in the correlation coefficient between Freundlich and Langmuir models. The adsorption data fits reasonably well for both Langmuir and Freundlich models.

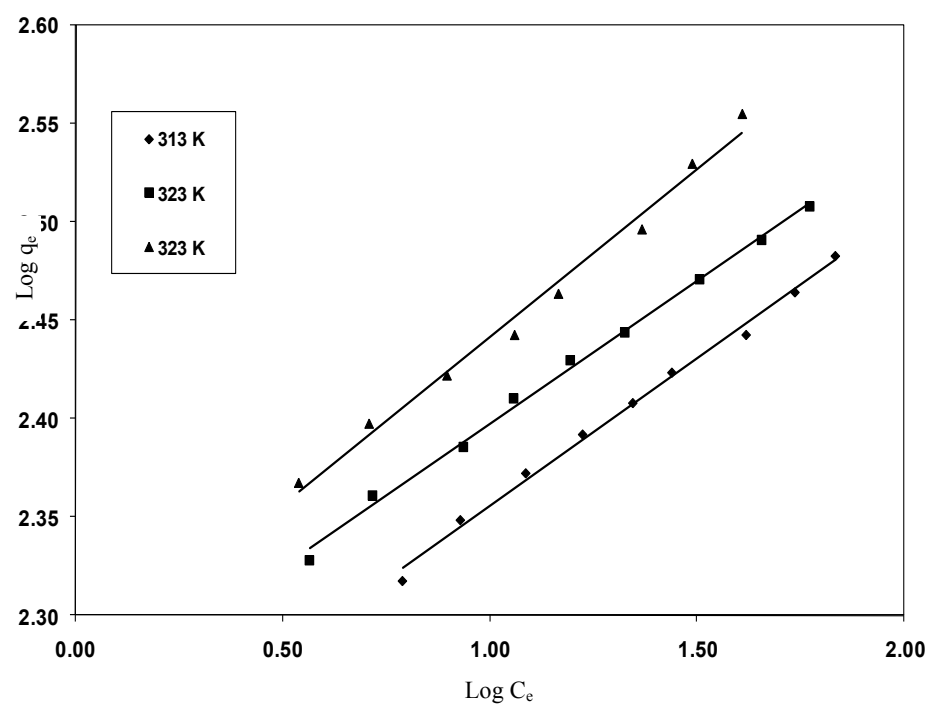

Figure 12. Freundlich isotherm for the adsorption AG 25 on to ACC at various temperature.

\section{Tempkin Isotherm}

Tempkin adsorption isotherm model was used to evaluate the adsorption potential of the ACC for AG 25. The derviation of the Tempkin isotherm assumes that the fall in the heat of sorption is linear rather than logarithmic, as implied in the Freundlich equation. The Tempkin isotherm has commonly been applied in the following form ${ }^{28-30}$.

$$
\mathrm{q}_{\mathrm{e}}=\mathrm{RT} / \mathrm{b} \ln \left(\mathrm{AC}_{\mathrm{e}}\right)
$$

The Tempkin isotherm Eq. (7) can be simplified to the following equation:

$$
\mathrm{q}_{\mathrm{e}}=\beta \ln \alpha+\beta \ln \mathrm{C}_{\mathrm{e}}
$$

A plot $\ln \mathrm{C}_{\mathrm{e}} V s \mathrm{q}_{\mathrm{e}}$ gives a striaght line as shown in Figure 13 with a slope of $\beta$ and intercept of $\beta \ln \alpha$. The parameters $\alpha$ and $\beta$ were given in Table. 3 . Where $\beta=(\mathrm{RT}) / \mathrm{b}, \mathrm{T}$ is the absolute temperature in Kelvin and $\mathrm{R}$ is the universal gas constant $8.314 \mathrm{~J}(\mathrm{~mol} \mathrm{~K})^{-1}$. The constant $\mathrm{b}$ is related to the heat of adsorption ${ }^{31,32}$. The adsorption data were analyzed according to the linear form of the Tempkin isotherm equation (8). Examination of the data shows that the Tempkin isotherm fitted well the AG 25 adsorption data for ACC. The correlation coefficient $\mathrm{R}^{2}$ obtained from Tempkin model were comparable to that obtained for Langmuir and Freundlich equations, which explains the applicability of Tempkin model to the adsorption of AG 25 onto ACC. 


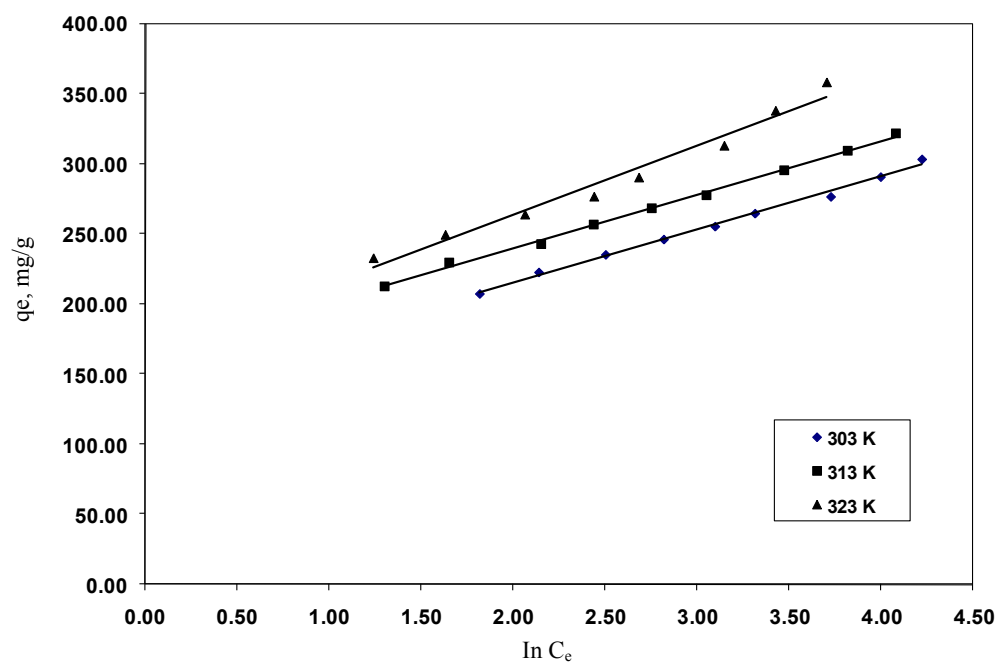

Figure 13. .Tempkin isotherm for the adsorption AG25 on to ACC at various Temperatures.

Table 3. Results of various isotherm plots for the adsorption of AG 25 on to ACC.

\begin{tabular}{lccc}
\hline Temperature, $\mathrm{C}$ & 30 & 40 & 50 \\
\hline Langmuir & & & \\
$\mathrm{Q}_{0}, \mathrm{mgg}^{-1}$ & 303.03 & 322.58 & 357.14 \\
$\mathrm{~b} \times 10^{-3}, \mathrm{Lmg}^{-1}$ & 6.49 & 6.125 & 5.55 \\
$\mathrm{R}_{\mathrm{L}}$ & 0.4118 & 0.4259 & 0.4501 \\
$\mathrm{~K}_{\mathrm{L}}$ & 1.9666 & 1.9758 & 1.9828 \\
$\mathrm{r}^{2}$ & 0.9942 & 0.9955 & 0.9891 \\
Freundlich & & & \\
$1 / \mathrm{n}$ & 0.1498 & 0.1453 & 0.1705 \\
$\mathrm{n}$ & 6.6755 & 6.8829 & 5.865 \\
$\mathrm{k}_{\mathrm{f}}, \mathrm{mg}^{1-1 / \mathrm{n}} \mathrm{L}^{1 / \mathrm{n}} \mathrm{g}^{-1}$ & 160.62 & 178.648 & 186.63 \\
$\mathrm{r}^{2}$ & 0.9949 & 0.9962 & 0.9879 \\
$\mathrm{Tempkin}$ & & & \\
$\alpha, \mathrm{Lg}^{-1}$ & 39.510 & 68.679 & 28.037 \\
$\beta, \mathrm{mgL}^{-1}$ & 37.962 & 38.492 & 49.485 \\
$\mathrm{~b}$ & 0.01506 & 0.01479 & 0.01479 \\
$\mathrm{r}^{2}$ & 0.9949 & 0.9973 & 0.9721 \\
\hline
\end{tabular}

\section{Thermodynamics of Adsorption}

Thermodynamic parameters like $\Delta \mathrm{H}^{\circ}, \Delta \mathrm{S}^{\circ}$ and $\Delta \mathrm{G}^{\circ}$ were calculated from the following Van't Hoff plot. 


$$
\ln k_{L}=\frac{\Delta S^{0}}{R}-\frac{\Delta H^{0}}{R} \frac{1}{T}
$$

The values of $\Delta \mathrm{H}^{\circ}$ and $\Delta \mathrm{S}^{\circ}$ are calculated from the slope and intercepts of the linear plot of $\ln \mathrm{k}_{\mathrm{L}} V s \mathrm{~s} / \mathrm{T}$ are shown in Figure 14. The free energy of specific adsorption $\Delta \mathrm{G}^{\circ}\left(\mathrm{kJ} \mathrm{mol}^{-1}\right)$ is calculated from the following expression.

$$
\Delta \mathrm{G}^{\mathrm{o}}=\Delta \mathrm{H}^{\mathrm{o}}-\mathrm{T} \Delta \mathrm{S}^{\mathrm{o}}
$$

The negative value of $\Delta G^{\circ}$ (Table.4) indicates the feasibility of the process and its spontaneous nature. If adsorption takes place spontaneously, then the free energy must diminish during the process so that $\Delta \mathrm{G}^{\circ}$ must have a negative value. The negative value of $\Delta \mathrm{H}^{\circ}$ for the system confirms the exothermic nature of adsorption. Similar results were reported for the adsorption of Methylene blue by red mud and Malachite green by Neem saw dust ${ }^{33,34}$. Physical adsorption is an exothermic process, which occur during physico chemical process such as adsorption.

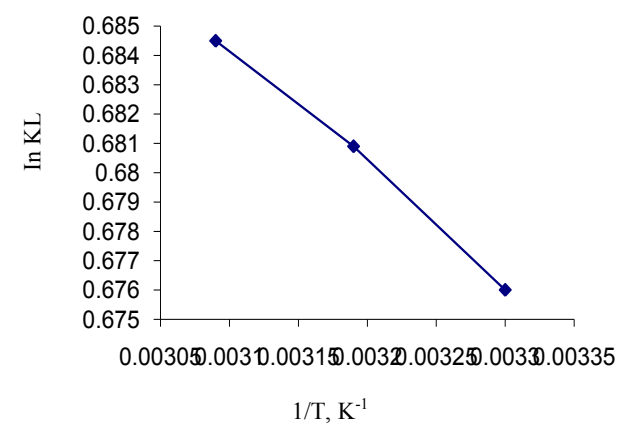

Figure 14. Van't Hoff plot for the adsorption AG 25 on to ACC at 303, 313 and $323 \mathrm{~K}$.

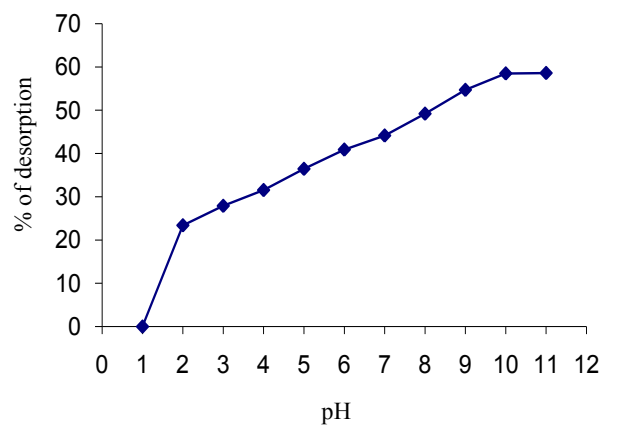

Figure 15. Percentage of desorption of AG 25 from ACC.

The positive value of $\Delta \mathrm{S}^{\circ}$ observed for the adsorption of dye molecules suggested the increased randomness at the solid-solution interface during adsorption process. The dye molecules in the aqueous media are hydrated. When the dye molecule get adsorbed on the adsorbent surface, the water molecules previously hydrogen bonded to the dye molecules get released and dispersed in the solution, this results in an increased in the entropy. The positive values of entropy changes also reflect good affinity of the dye towards the adsorbent. The entropy changes in the present study are in excellent agreement with adsorption of methylene blue on red mud $^{33}$, wheat shell ${ }^{35}$ and alumina ${ }^{36}$.

\section{Desorption Studies}

Desorption studies as a function of $\mathrm{pH}$ was conducted to explore the possibility of recovery of adsorbent and adsorbate. If the adsorbed dyes can be desorbed from the activated carbon by using neutral $\mathrm{pH}$ water, then the attachment of the dyes on the adsorbent is weak. If sulphuric acid or alkaline water desorbs the dyes, then the adsorption is by ion exchange. If organic acids, like acetic acid desorp the dyes, then the dye is attached to the adsorbent through chemisorptions. In this study, $\mathrm{HCl}$ acid is better reagent for desorption because we 
could get almost 59\% removal of adsorbed dyes. The reversibility of adsorbed dyes in mineral acid or base is in agreement with the $\mathrm{pH}$ dependent results obtained. The desorption of dyes by mineral acids and alkaline medium indicates that the dyes are adsorbed onto the activated carbon by physisorption ${ }^{37,38}$.

\section{Conclusion}

Activated carbon prepared from Ananas Comosus (L) leaves by chemical activation with $\mathrm{H}_{3} \mathrm{PO}_{4}$ can be conveniently used for the adsorption of Acid Green 25. The $\mathrm{H}_{3} \mathrm{PO}_{4}$ activated carbon has the surface area of $908 \mathrm{~m}^{2} \mathrm{~g}^{-1}$. The adsorbed amount of AG 25 decreased with increasing $\mathrm{pH}$ from 2 to 11 and increased with increasing concentration, contact time and temperature. The adsorption of AG 25 onto ACC follows pseudo second order kinetics. The moderate uptake of dye indicates that the rate determining step could be physisorption in nature. Intra particle diffusion model proves that pore diffusion plays major role in the dye adsorption. The experimental data correlated reasonably well with the Langmuir, Freundlich and Tempkin adsorption isotherm with good correlation coefficient. The negative enthalpy proves that the adsorption of AG 25 onto ACC is exothermic in nature.

Table 4. Thermo dynamical parameters for the adsorption of AG 25 onto ACC.

\begin{tabular}{cccc}
\hline Temperature ${ }^{\circ} \mathrm{K}$ & $\Delta \mathrm{H}^{\mathrm{o}}, \mathrm{kJ} / \mathrm{mol}$ & $\Delta \mathrm{S}^{\mathrm{o}}, \mathrm{J} / \mathrm{K} / \mathrm{mol}$ & $\Delta \mathrm{G}^{\mathrm{o}}, \mathrm{kJ} / \mathrm{mol}$ \\
\hline 303 & & & -1.015 \\
313 & -1.3876 & 2.893 & -1.044 \\
323 & & & -1.073 \\
\hline
\end{tabular}

\section{References}

1. Reife A, in: Kroschwitz J I and Howe-Grant (Eds.), Kirk-Othmer Encyclopedia of Chemical Technology, fourth Ed., Wiley, New York, 1993, 6.

2. Pelaez.Cid A A, Ph.D. Thesis, Universidde Autonoma de Puebia, Mexico, 2004 (in Spanish).

3. Giris B S, Yunis S S and Soliman, Mater Lett., 2002, 57, 164.

4. Gupta V K and Ali I, in: Somasundram P, Ed., Adsorbents for Water Treatment: Development of low cost Alternatives to Carbon. Encyclopedia Surface Colloid Science, 2003.

5. Sh Juang R, Ch Wu F and Tseng R L, Colloid Surf A: Physicochem Eng Asp., 2002, 201, 191.

6. Kannan N and Sundaram M M, Dyes and Pigments, 2001, 51, 25.

7. Rajeshwarisivraj, Sivakumar S, Senthilkumar P and Subburam V, Bioresource Technol., 2001, 80, 233.

8. Wc F C, Tseng R L and Juang R S, Environ Technol., 2001, 22, 205.

9. Girgis B S and Ishak M F, Mter Lett., 1999, 39, 107.

10. $\mathrm{Hu} \mathrm{Zu,} \mathrm{Srinivasan} \mathrm{M} \mathrm{P} \mathrm{and} \mathrm{Ni} \mathrm{Y,} \mathrm{Carbon.,} \mathrm{2001,} \mathrm{39,} 877$.

11. Wu Ch F, Tseng R L and Juang Sh, J Hazard Mater B, 1999, 69, 287.

12. Juang Sh R, Wu F Ch and Tseng R L, J Colloid Interf Sci., 2000, 227, 437.

13 Malik P K, Dyes Pigments, 2003, 56, 239.

14. Malik P K, J Hazard Mater B, 2004, 113, 81.

15. American Society for Testing and Materials (ASTM), 1996a. Standard test method for $\mathrm{pH}$ of activated carbon (D-3838) In: Annual Book of ASTM standards, vol15.03 Philadelphia, USA, pp. 531- 532. 
16. Hsieh C T and Teng H, J Colloid Interf Sci., 2000, 230, 171.

17. Sathy Chandrasekhar and Pramada P N, Adsorption, 2006, 12, 27-43.

18. Iqbal M J and Hussain M, J Chem Soc Pak., 1993, 15 (1), 7- 10.

19. Iqbal M J, et al., J Chem Soc Pak., 1993, 15(1), 93-97.

20. Hameed B H and Hakini H, Biochem Eng J., 2008, 39, 338-343.

21. Lagergren S, Kung Sven Veren Hand. 1898, 24, 1-39.

22. Purkait M K, Gusain D S, DasGupta S and De S, Sep Sci Technol., 2004, 39(10), 2419-2440.

23. Nandi B K, Goswami A and Purkait M K, J Hazard Mater., 2009, 161, 387-395.

24. Weber Jr W J and Morriss J C, J Sanit Eng Div Am Soc Civil Eng. 1963, 89, 31-60.

25. Noroozi B, Sorial G A, Bahrami H and Arami M, J Hazard Mater., 2007, B139, $167-$ 174.

26. Langmuir I, J Am Chem Soc., 1918, 40, 1361-1403.

27. Freundlich H, Z Physik Chem., 1906, A57, 385-470.

28. Aharoni C and Sparks D L, kinetics of soil chemical reactions- a theoretical treatment, in: Sparks D L and Suarez D L, (Eds.), Rate of Soil Chemical Process, Soil Science Society of America, Madison, Wt, 1991, 1-18.

29. Aharoni C and Ungarish M, J Chem Soc Faraday Trans., 1977, 73, 456-464.

30. Wang X S and Qjn Y, Process Biochem., 2005, 40, 677-680.

31. Akkaya G and Ozer A, Process Biochem., 2005, 40(11), 3559-3568.

32. Pearce C I, Lioyd J R and Guthrie J T, Dyes Pigments, 2003, 58, 179-196.

33. Ramesh A, Lec D J and Wang J W C, J Coll Inter Sci., 2005, 291, 588.

34. Khattri S D and Singh M K, Water Air Soil Pollution, 2000, 120, 283.

35. Bulut Y and Aydin H, Desalination, 2006, 194, 259.

36. Muhammad Javed Iqbal and Muhammad Naeem Ashiq, J Chem Soc Pak., 2010, 32(4), 419.

37. Arivoli S, Venkatraman B R, Rajachandrasekar T, E-J Chem., 2007, 4, 238.

38. Sreedhar M K, Anirudhan T S, Indian J Environ Prot., 1999, 19, 8. 


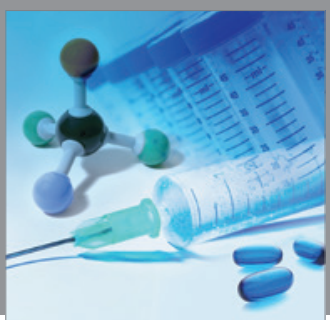

International Journal of

Medicinal Chemistry

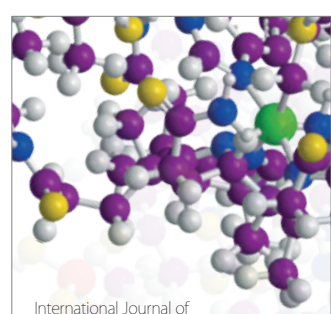

Carbohydrate Chemistry

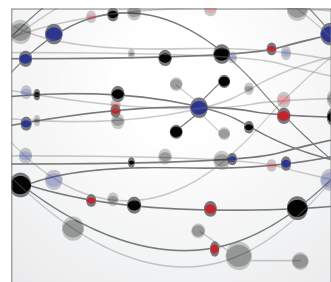

The Scientific World Journal
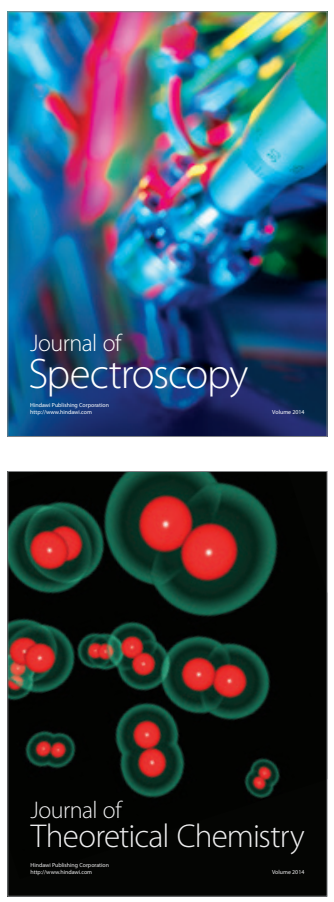
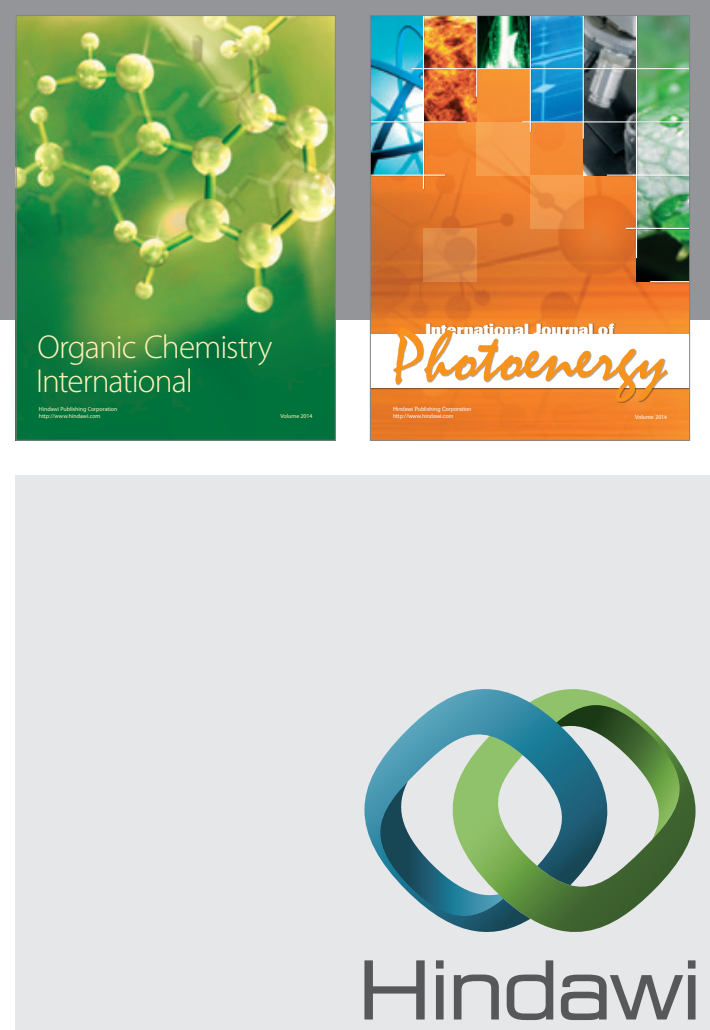

Submit your manuscripts at

http://www.hindawi.com
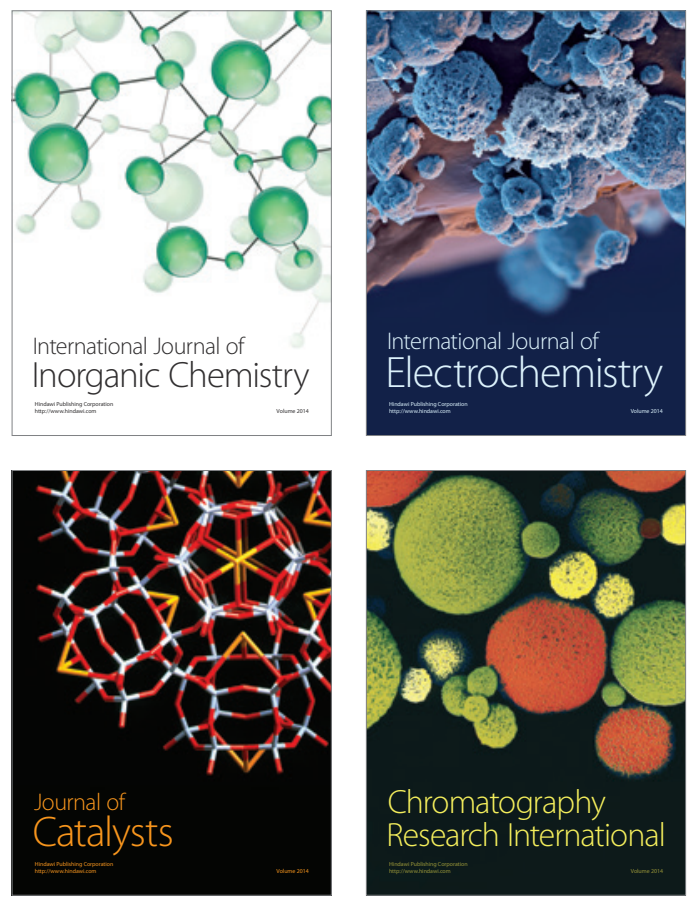
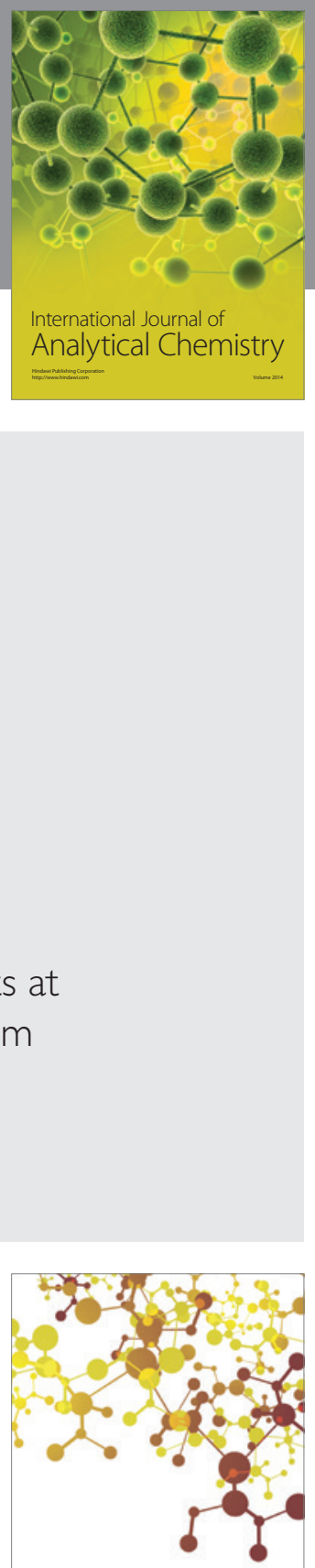

Journal of

Applied Chemistry
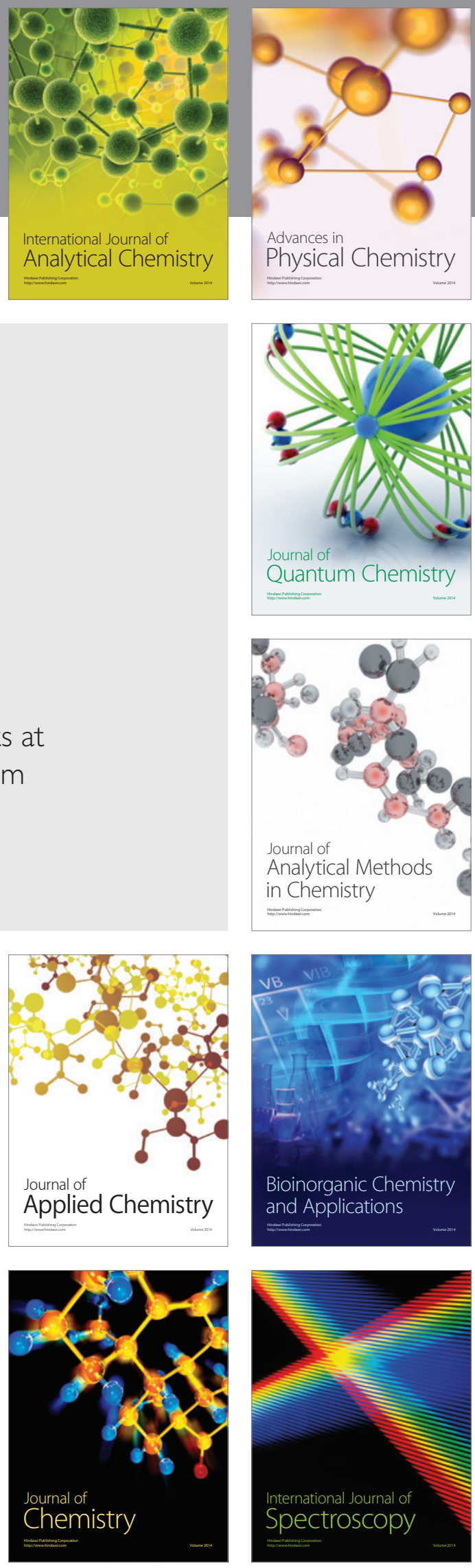